\title{
QUALIDADE MICROBIOLÓGICA E FÍSICO-QUÍMICA DE QUEIJOS COLONIAIS COM E SEM INSPEÇÃO, COMERCIALIZADOS NO SUDOESTE DO PARANÁ
}

\author{
FRANCIELE DA SILVA* \\ GISELE DA SILVA** \\ IVANE BENEDETTI TONIAL*** \\ FABIANE PICININ DE CASTRO-CISLAGHI****
}

\begin{abstract}
O queijo colonial é um queijo artesanal, produzido em propriedades rurais, geralmente fabricado com leite cru e muitas vezes sem boas práticas de fabricação. Não possui regulamento técnico de identidade e qualidade e em muitos casos não possui inspeção. O objetivo deste trabalho foi avaliar as características físico-químicas e a qualidade microbiológica de amostras de queijos coloniais sem inspeção, com inspeção federal, estadual e municipal comercializados no Sudoeste do Paraná. Foram coletadas oito amostras de queijo colonial, sendo duas de cada serviço de inspeção e duas sem inspeção. Foram realizadas análises físico-químicas $(\mathrm{pH}$, acidez, umidade, proteínas, lipídeos, gordura no extrato seco, extrato seco desengordurado, cinzas e carboidratos totais) e microbiológicas (mesófilos aeróbios, bolores e leveduras, coliformes totais e termotolerantes, Staphylococcus coagulase positiva e Salmonella sp.). Os resultados das análises microbiológicas demonstraram que $50 \%$ das amostras estavam com contagens de coliformes totais e termotolerantes acima do permitido pela legislação, sendo duas amostras de inspeção municipal e duas sem inspeção. Por meio das análises físico-químicas, foi possível observar a falta de padronização dos queijos coloniais, o que é indesejável tanto para os produtores, quanto para os consumidores. Dessa forma, os resultados indicam a necessidade de maior controle de qualidade do processo e do produto final, bem como a elaboração de um regulamento técnico de identidade e qualidade do queijo colonial.
\end{abstract}

PALAVRAS-CHAVE: LEITE CRU; QUEIJO COLONIAL; LÁCTEO; CONTAMINAÇÃO; INSPEÇÃO.

*Tecnóloga em Alimentos, Universidade Tecnológica Federal do Paraná (UTFPR), Francisco Beltrão, PR (e-mail: fran.alimentos@gmail.com).

**Discente do curso de Tecnologia em Alimentos, Universidade Tecnológica Federal do Paraná (UTFPR), Francisco Beltrão, PR (e-mail: giseleutfpr@hotmail.com).

***Doutora em Química, Docente, Curso de Tecnologia em Alimentos, Universidade Tecnológica Federal do Paraná (UTFPR), Francisco Beltrão, PR (email: ivane@utfpr.edu.br)

****Doutora em Ciência de Alimentos, Docente, Curso de Tecnologia em Alimentos, Universidade Tecnológica Federal do Paraná (UTFPR), Francisco Beltrão, PR (e-mail: fabianecastro@utfpr.edu.br) 


\section{INTRODUÇÃO}

Dentre os derivados lácteos, o queijo é um dos mais procurados e consumidos, visto que apresenta em sua composição consideráveis teores de proteínas de alto valor biológico, sais minerais, vitaminas e lipídios (ABIQ, 2014). Tanto no Brasil quanto no mundo todo, o queijo é um dos produtos lácteos que mais se difundiu e sofreu adaptações nas técnicas de elaboração, ocasionando o surgimento de vários tipos (MAGALHÃES, 2002).

A classificação dos queijos baseia-se em características decorrentes do tipo de leite utilizado, tipo de coagulação, consistência da pasta, teor de gordura, tipo de casca, tempo de maturação, dentre outros (PERRY, 2004). Queijos do tipo artesanal podem ser definidos como queijos cuja produção segue os métodos tradicionais, porém de forma rudimentar, à margem da legislação vigente, sem controles de qualidade, sendo comercializados, na maioria das vezes, de maneira informal (SEBRAE, 2008).

O queijo Colonial é um tipo de queijo artesanal. No sudoeste do Paraná, o queijo Colonial é um dos mais procurados e aceitos pela população, uma vez que tem origens antigas e se tornou parte da cultura dos indivíduos nessa região. É uma variedade que surgiu como uma alternativa para agregar valor à produção de leite e aumentar a renda dos pequenos produtores. Segundo Sebrae (2008), este queijo é originário do Brasil, com sabor mediamente picante e período de maturação de 30 dias.

O queijo é considerado um veículo frequente de microrganismos patógenos de origem alimentar, e principalmente, os queijos frescos produzidos de maneira artesanal, que na sua maioria, são elaborados com leite cru, sendo que, quase na sua totalidade, são consumidos sem maturação. A contaminação microbiana desses produtos assume destacada relevância tanto para a indústria, pelas perdas econômicas, como para a saúde pública, pelo risco de causar doenças transmitidas por alimentos contaminados (FEITOSA et al., 2003).

Não existe padrão de técnicas de fabricação do queijo colonial, bem como Regulamento Técnico de Identidade e Qualidade (RTIQ) deste tipo de queijo. O queijo Colonial é amplamente produzido artesanalmente pelos agricultores do Paraná, com tecnologia semelhante àquela do queijo Minas, porém dados exatos a respeito da composição, tecnologia, produção e comercialização são poucos e sua fabricação clandestina é frequente.

Tendo em vista o alto consumo de queijos coloniais frescos na região Sudoeste do

Paraná, faz-se necessária a avaliação da qualidade desses produtos. Alguns estudos tem sido conduzidos sobre a qualidade do queijo colonial (ROOS et al., 2005; ANTONELLO, KUPKOVSKI e BRAVO, 2012; JÚNIOR et al., 2012; LUCAS et al., 2012; OLIVEIRA et al., 2012), no entanto a relação da qualidade com o tipo de inspeção desse queijo foi investigada somente por Dias (2010), que avaliou apenas a qualidade microbiológica. O objetivo deste trabalho foi avaliar as características físico-químicas e a qualidade microbiológica de amostras de queijos coloniais sem inspeção, com inspeção federal, estadual e municipal comercializados no Sudoeste do Paraná.

\section{MATERIAL E MÉTODOS}

As amostras de queijo foram adquiridas no período de junho a julho de $2013 \mathrm{em}$ supermercados e feiras-livres na região de Francisco Beltrão, sudoeste do Paraná. Foram coletadas oito amostras de queijo colonial, sendo duas de cada serviço de inspeção (municipal, estadual e federal), de marcas distintas e duas de fabricação artesanal (sem inspeção), de dois produtores diferentes. As amostras foram transportadas em caixas hermeticamente fechadas até o Complexo de Laboratórios da Universidade Tecnológica Federal do Paraná - UTFPR, câmpus Francisco Beltrão, onde foram realizadas as análises físico-químicas. As análises microbiológicas foram realizadas no 
Laboratório de Análises Agroindustriais (LAQUA) da UTFPR, câmpus Pato Branco. As amostras de queijo foram mantidas sob refrigeração.

No preparo das amostras primeiramente foi removida a casca do queijo com uma faca, tomando porções de diferentes pontos da amostra e foi feita a homogeneização em um gral (INSTITUTO ADOLFO LUTZ, 2008).

As análises físico-químicas de $\mathrm{pH}$, acidez em ácido lático, umidade em estufa a $105^{\circ} \mathrm{C}$, cinzas em mufla a $550^{\circ} \mathrm{C}$ e lipídeos pelo método de Soxhlet foram realizadas de acordo com as normas do Instituto Adolfo Lutz (2008). A determinação de proteínas foi feita pelo método semimicro Kjeldahl descrito por Tedesco et al. (1995). A gordura no extrato seco (GES) (PEREIRA et al., 2001), o extrato seco desengordurado (ESD) (ANDRADE, 2006) e carboidratos totais (por diferença) (AOAC, 2005) foram obtidos por cálculo.

As análises microbiológicas de mesófilos aeróbios, bolores e leveduras, Número Mais Provável de coliformes totais e termotolerantes, Staphylococcus coagulase positiva e Salmonella sp. foram realizadas de acordo com a metodologia estabelecida pela Instrução Normativa $n^{\circ} 62 / 2003$ do Ministério da Agricultura, Pecuária e Abastecimento (MAPA) (BRASIL, 2003).

Todas as análises foram realizadas em triplicata e os resultados foram submetidos à análise de variância (ANOVA) a $5 \%$ de probabilidade, e teste de Tukey, através do software Statistica, versão 7.0 (2004, Statsoft Inc, Tulsa, Ok, EUA).

\section{RESULTADOS E DISCUSSÃO}

$\mathrm{Na}$ fabricação industrial dos queijos coloniais, geralmente ocorre o emprego de boas práticas de fabricação, a adição de culturas láticas para uma padronização e uniformidade dos queijos e o leite utilizado é pasteurizado a fim de atender a legislação, uma vez que estes queijos geralmente são consumidos frescos. Isso nem sempre ocorre quando os queijos coloniais são produzidos artesanalmente.

A Tabela 1 apresenta os resultados das análises físico-químicas das amostras de queijos coloniais com e sem inspeção. Observou-se que há falta de padronização do processo de fabricação, ocasionando a oferta de diferentes produtos ao consumidor. Os valores médios de $\mathrm{pH}$ dos queijos analisados variaram de 5,41 - 5,74 entre os queijos classificados como brandos/alta umidade (SI1, SI2, IM1 e IM2), e 5,51 - 5,90 para os queijos semiduros/média umidade (IE1, IE2, IF1 e IF2) (Tabela 1). Os queijos SI2 e IE1 apresentaram os pHs mais elevados. Segundo Scott, Robinson e Wilbey (2002), o pH dos queijos varia entre 5,5 - 5,8 para queijos brandos e 5,3-5,4 para queijos semiduros. Para os queijos classificados como brandos o pH encontrado está em uma faixa semelhante à descrita por Scott, Robinson e Wilbey (2002), porém para os queijos classificados como semi-duros o pH está acima da faixa estipulada. Segundo o mesmo autor, o que pode ter ocorrido é a prensagem ineficiente com muita retenção de soro, a adição excessiva de sal ou a venda do queijo muito fresco. De acordo com Noronha (2014), a redução do pH do queijo, para valores entre 4,5 e 5,5, contribui para a prevenção do crescimento de bactérias patogênicas e da maioria dos microrganismos implicados na deterioração do queijo.

A partir dos resultados, pode-se observar que a variação no $\mathrm{pH}$ não foi tão acentuada quanto à observada em trabalhos similares. Júnior et al. (2012) avaliaram diferentes marcas de queijos coloniais comercializados na região sudoeste paranaense e observaram valores médios de $\mathrm{pH}$ que variaram entre 3,92 e 5,81.

Os valores de acidez variaram de 0,09 a 0,55 (\% ácido lático) (Tabela 1). Pode-se observar uma grande variação entre as amostras, sendo que as maiores médias foram apresentadas pelas amostras IF2, IF1 e IE2. A amostra IE1, apesar de ser de inspeção estadual, não apresentou resultado semelhante, sendo que a acidez observada foi de $0,32 \%$. As menores médias de acidez 
foram das amostras sem inspeção e com inspeção municipal; a baixa acidez, aliada à elevada umidade, favorece o crescimento de microrganismos como os coliformes, o que foi confirmado pelas análises microbiológicas destas amostras de queijos (Tabela 2).

Em estudo realizado por Oliveira, Bravo e Tonial (2012), na região sudoeste do Paraná, foram encontrados valores médios entre 0,24 e 1,15\% de ácido lático. Júnior et al. (2012) também com estudos na região, encontraram médias entre 0,35 e $0,87 \%$ de ácido lático. Em comparação com os resultados obtidos, os queijos com inspeção federal e estadual apresentaram valores próximos aos dos outros estudos na região. Em contrapartida, os queijos sem inspeção e com inspeção municipal obtiveram porcentagens abaixo dos descritos por estes autores. A baixa acidez pode ser explicada pelos altos índices de carboidratos encontrados nesses queijos, que ainda não foram convertidos em ácido lático, em virtude de estes queijos encontrarem-se muito frescos. Além disso, segundo Júnior et al. (2012), os queijos artesanais, por serem, na maioria das vezes, prensados manualmente, apresentam retenção de soro desuniforme, interferindo na quantidade de lactose eliminada no soro, o que interfere na acidez final. Outro fator que pode explicar a baixa acidez apresentada pelos queijos sem inspeção e com inspeção municipal é a não utilização de fermento lático pela grande maioria desses laticínios.

A umidade dos queijos variou de 37,52 a 48,09\% (Tabela 1). As amostras que apresentaram as maiores médias foram as sem inspeção e com inspeção municipal, sendo que a menor média foi do queijo IF1. De acordo com a legislação vigente (BRASIL, 1996), quanto à umidade os queijos sem inspeção e com inspeção municipal foram classificados como queijos de alta umidade/massa branda, com umidade entre 46,0 e $54,9 \%$. Os queijos com inspeção estadual e federal foram classificados como queijos de média umidade/massa semi-dura, pois apresentaram umidade entre 36,0 e $45,9 \%$.

De acordo com Scott, Robinson e Wilbey (2002), a variação do teor de umidade se deve ao tipo de prensagem, tamanho dos queijos e o tempo de maturação dos mesmos. Diferentes resultados foram encontrados por Oliveira, Bravo e Tonial (2012) para queijos coloniais da região, onde os teores de umidade variaram entre $63,34 \%$ e $79,88 \%$, sendo classificados como queijos com muito alta umidade/massa mole.

Em comparação com os resultados microbiológicos (Tabela 2), os queijos com maior teor de umidade (SI1, SI2, MI1 e MI2) apresentaram elevada contaminação microbiana por coliformes totais e termotolerantes. Segundo Cecchi (2003), queijos com maior umidade são mais propícios à contaminação e desenvolvimento microbiano, deteriorando mais rápido e diminuindo a vida de prateleira.

O conteúdo de proteína das amostras variou de 16,74 a 28,35\% (Tabela 1). A amostra SI1 apresentou a menor quantidade de proteínas em relação às demais $(p<0,05)$, sendo que as amostras com inspeção federal obtiveram as maiores médias. Os valores observados para os queijos das inspeções municipal e estadual foram similares aos encontrados por Oliveira (2011) e Júnior et al. (2012). Já o estudo de Junior, Penteado e Fariña (2010), que avaliou a qualidade do queijo colonial produzido pela agricultura familiar do oeste e sudoeste do Paraná, encontrou variação de 25,03 $29,80 \%$ de proteína, médias altas e com pouca variação em relação aos resultados encontrados. A caseína é a principal proteína do queijo, e as diferentes quantidades no produto final se devem à perda proteica durante o processo de dessora (SCOTT, ROBINSON e WILBEY, 2002), ocasionando diminuição do rendimento.

As diferenças no percentual de proteínas podem ser decorrentes das etapas de fabricação do queijo, entre elas, o tipo de salga, o tempo de maturação, bem como a quantidade de coalho adicionada à massa, pois se em excesso, pode ocasionar maior proteólise, implicando na redução do teor de proteínas (SPREER, 1991). Desta forma, juntamente com as demais análises físicoquímicas realizadas, pode-se observar a falta de padronização do processo de fabricação, o que resulta em produtos com características distintas. 


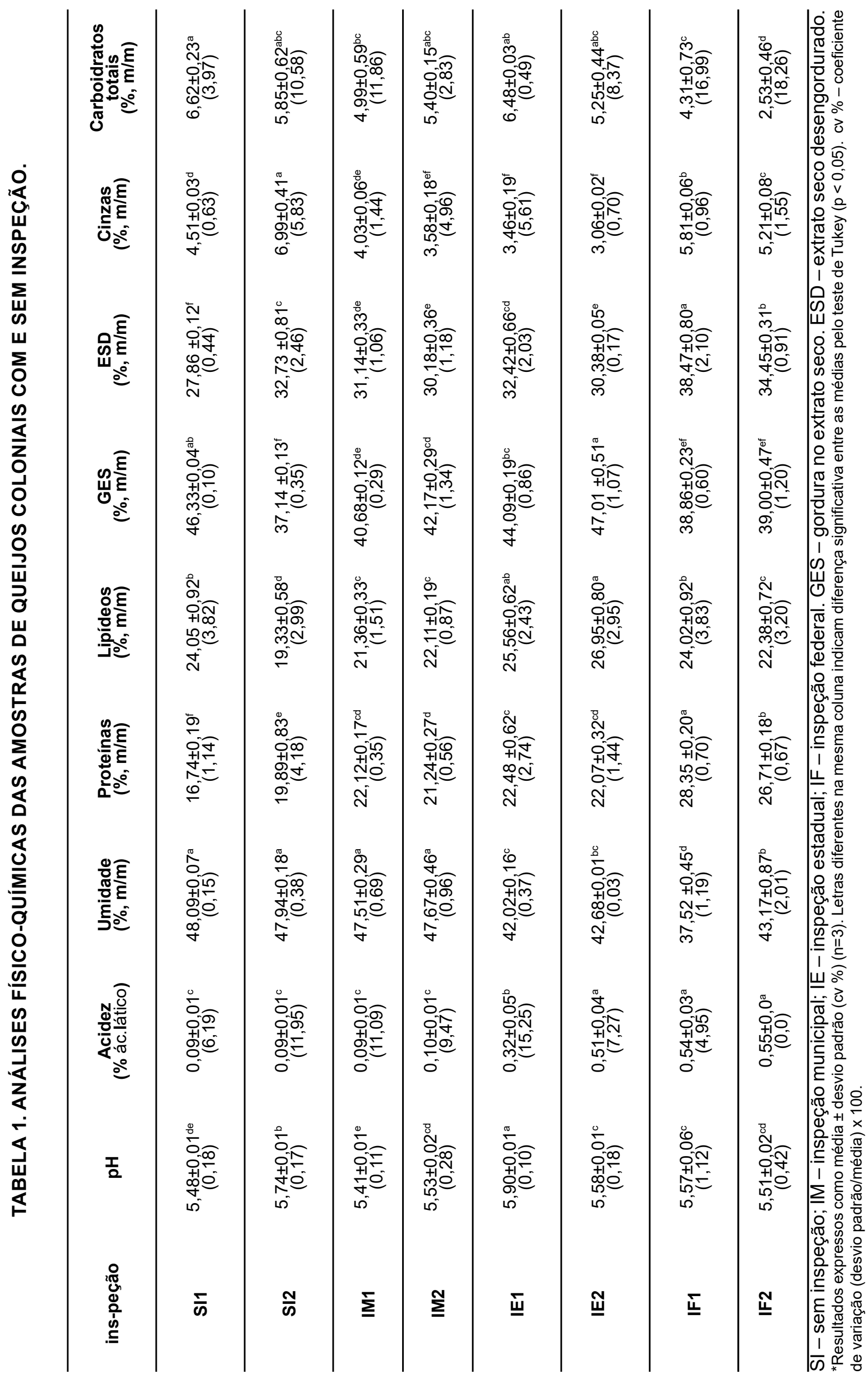


Os teores de lipídeos das amostras variaram entre 19,33\% e 26,95\% (Tabela 1), resultados semelhantes à Lucas et al. (2012) e Oliveira, Bravo e Tonial (2012), que em seus estudos, os teores de lipídeos variaram entre $15,43 \%-26,53 \%$ e $12,06 \%-24,12 \%$, respectivamente. Júnior et al. (2012) observaram maiores teores de lipídeos em queijos coloniais, com uma variação de 21,12 $31,32 \%$.

Devido ao fato de que o queijo colonial não possui regulamento técnico de identidade e qualidade, cada indústria pode definir sua formulação e tecnologia de fabricação, o que interfere no teor de gordura desses queijos. Segundo Costa et al. (1992) a composição do queijo varia com a composição do leite do qual é obtido, que pode apresentar diferenças significativas no seu teor de gordura se o leite for coletado pela manhã ou à tarde. Isso pode ser mais relevante nos queijos sem inspeção e com inspeção municipal, os quais, na maioria das vezes, são fabricados com o teor de gordura original do leite ou ainda é feito um "desnate natural", através da separação da gordura na superfície devido ao repouso do leite por várias horas, sob refrigeração. Esses laticínios não possuem a desnatadeira, equipamento utilizado para padronização do teor de gordura do leite. As empresas com inspeção estadual e federal, na maioria das vezes, fazem essa padronização, pois o creme resultante pode ser comercializado ou ainda utilizado na elaboração de outros derivados.

De acordo com Andrade (2006) o teor de gordura de um queijo é melhor analisado quando expresso em relação ao extrato seco total, impedindo-se que ocorram variações ocasionadas por uma eventual perda de umidade. Segundo o Regulamento Técnico de Identidade e Qualidade de Queijos (BRASIL, 1996), os queijos podem ser classificados quanto ao conteúdo de gordura no extrato seco (GES) (\%). De acordo com essa classificação, os queijos com inspeção municipal e federal, uma amostra de inspeção estadual (IE1) e uma sem inspeção (SI2) foram classificados como queijos semi-gordos, uma vez que seus conteúdos de GES estão entre 25,0 e 44,9\%, estabelecidos pela legislação. Em contrapartida as outras amostras de queijo sem inspeção (SI1) e com inspeção estadual (IE2), apresentaram conteúdo de gordura no extrato seco entre $45,0-59,99 \%$, sendo classificadas desta forma como queijos gordos.

No estudo de Lucas et al. (2012), foi observada uma variação de GES de 32,73 $48,78 \%$, sendo que três amostras de queijos coloniais foram classificadas como gordos e apenas uma amostra classificada como semi-gordo. Já no estudo de Júnior et al. (2012) houve uma variação entre 42,10 - 59,38 \% no teor de GES, sendo que do total de 24 amostras apenas uma foi classificada como queijo semi-gordo, sendo as demais classificadas como queijos gordos.

A partir dos resultados encontrados, observa-se que não há uma padronização na composição destes queijos, o que influencia na porcentagem final de gordura e umidade e consequentemente na classificação quanto ao teor de gordura no extrato seco.

Os valores de extrato seco desengordurado (ESD) variaram de 27,86 a 38,47 (Tabela 1). Pode-se observar que a amostra com maior média foi a IF1 $(38,47 \%)$, seguida pela amostra IF2 $(34,45 \%)$. Isso se deve ao fato de que estas amostras apresentaram teores elevados de proteínas, o que refletiu em maiores valores de $\operatorname{ESD}(p<0,05)$. A variação do nível de proteína do leite é o principal parâmetro que influencia na quantidade de ESD presente no queijo, o que evidencia a importância deste parâmetro para a avaliação do rendimento industrial dos queijos (RENEAU; PACKARD, 1991 apud VERZA, 2012).

O teor de cinzas teve uma variação de 3,06\% a 6,99\% (Tabela 1). Tal variação também foi evidenciada no trabalho de Oliveira, Bravo e Tonial (2012), cujo teor médio de cinzas variou entre $2,77 \%$ a $5,72 \%$ nas amostras de queijo. Segundo Cecchi (2003), o conteúdo de cinzas em produtos lácteos pode variar entre 0,7-6,0\%, sendo que nos queijos e produtos lácteos, há a presença de grandes quantidades de cálcio, fósforo e cloretos, devido aos ingredientes utilizados em sua fabricação e à matéria-prima utilizada. Dessa forma, as amostras de inspeção municipal, 
estadual, federal e a amostra SI1, estão de acordo com essa variação, porém a amostra SI2 está em desacordo, apresentando um valor de 6,99\% de cinzas.

Bittencourt (2011) atribui o alto teor de cinzas à quantidade de cloreto de sódio $(\mathrm{NaCl})$ adicionado à massa. Essa pode ser a causa do elevado teor de cinzas da amostra SI2, visto que não há padronização do processo de fabricação no momento da salga. Assim, a adição do cloreto de sódio (sal) se dá de maneira distinta em cada laticínio ou queijaria. Outro fator que pode alterar a quantidade de cinzas é a adição de cloreto de cálcio $\left(\mathrm{CaCl}_{2}\right)$ durante a fabricação dos queijos, o que é prática comum nos laticínios maiores, mas não é realizada para queijos sem inspeção ou com inspeção municipal, o que pode ser a causa do maior teor de cinzas dos queijos IF1 e IF2.

Os valores médios de carboidratos dos queijos analisados apresentaram grande variação, de 2,53 a 6,62\% (Tabela 1). Em estudos realizados na região por Oliveira (2011) e Júnior et al. (2012), foi observada uma variação de carboidratos entre $1,01-1,60 \%$ e $0,55-4,33 \%$, respectivamente. Nota-se que há uma variação considerável entre os valores encontrados nos estudos, o que pode ser atribuído ao processo utilizado na fabricação dos queijos, que interfere na quantidade de soro eliminada e na quantidade de ácido lático presente no produto final, uma vez que queijos mais frescos e com menor dessora possuem maior quantidade de carboidratos (SCOTT, ROBINSON e WILBEY, 2002).

Os resultados das análises microbiológicas dos queijos coloniais, com diferentes tipos de inspeção estão apresentados na Tabela 2. Por não possuir padrão de identidade e qualidade, o queijo colonial não possui limites estabelecidos quanto à contaminação microbiana, portanto, foi utilizado, para fins de comparação, o Regulamento Técnico Geral para a fixação dos requisitos microbiológicos de queijos (BRASIL, 1996). Foram comparados os parâmetros para queijos com média umidade (IE1, IE2, IF1, IF2) e alta umidade (SI1, SI2, IM1, IM2), segundo a classificação das amostras.

As médias de mesófilos aeróbios dos queijos analisados variaram de 3,04 (SI2) a 7,17 (IF1) log UFC. $\mathrm{g}^{-1}$. Os queijos com inspeção estadual e federal obtiveram maiores contagens que os queijos com inspeção municipal e sem inspeção, fator este que demonstra uma controvérsia, pois quanto maior a inspeção maior o nível de exigência de qualidade no processo, sendo que os resultados apontam melhor qualidade dos queijos com menor inspeção, neste aspecto. Existem poucos estudos na região sobre este grupo de microrganismos, porém Dias (2010) em seu estudo obteve resultados similares para queijo colonial, com médias entre 5,0 × $10^{2}$ a 2,25 $\times 10^{5} \mathrm{UFC} / \mathrm{g}$. Roos et al. (2005) ao avaliarem queijo colonial obtido em feiras livres na cidade de Três Passos-RS observaram resultados superiores que variaram de $1,5 \times 10^{7}$ a $2,5 \times 10^{10}$ UFC/g.

Não existe padrão na legislação, porém quanto maior o número de bactérias mesófilas, menor será a vida de prateleira do queijo colonial (PERRY, 2004). Elevadas quantidades de mesófilos em alimentos podem indicar que a matéria-prima utilizada estava altamente contaminada, que o processo foi insatisfatório do ponto de vista higiênico-sanitário ou que os alimentos foram armazenados em condições inadequadas de tempo e temperatura (LEITE JÚNIOR et al., 2000).

Em relação à contagem de bolores e leveduras, houve uma variação nos resultados entre as amostras analisadas, sendo que as médias variaram de 1,30 (IF1) a 6,38 (IF2) log UFC. - $^{-1}$. Dias (2010) obteve contagens de bolores e leveduras de $1,89 \times 10^{4}$ a 3,00 x $10^{5} \mathrm{UFC} / \mathrm{g}$, com pouca variação, em comparação aos resultados obtidos. Embora não exista padrão normativo de contagem de bolores e leveduras na legislação para queijos, a presença de bolores e leveduras contaminantes em queijos é indesejável. As altas contagens de bolores e leveduras encontradas sugerem que se faz necessário um controle maior da produção, em todo o processo, a fim de diminuir esses microrganismos no produto, os quais reduziriam a sua vida útil consideravelmente. 
TABELA 2. ANÁLISES MICROBIOLÓGICAS DAS AMOSTRAS DE QUEIJOS COLONIAIS COM E SEM INSPEÇÃO.

\begin{tabular}{|c|c|c|c|c|c|c|}
\hline $\begin{array}{l}\text { Tipos de } \\
\text { inspeção }\end{array}$ & $\begin{array}{c}\text { Mesófilos } \\
\text { aeróbios } \\
\text { (log UF- } \\
\left.\text { C. } \text { - }^{-1}\right)^{*}\end{array}$ & $\begin{array}{c}\text { Bolores e } \\
\text { Leveduras } \\
\quad(\log \\
\left.\text { UFC. }^{-1}\right)^{*}\end{array}$ & $\begin{array}{c}\text { Coliformes } \\
\text { totais } \\
(\text { NMP.g-1) }\end{array}$ & $\begin{array}{c}\text { Col.termo- } \\
\text { tolerantes } \\
(\text { NMP.g-1) }\end{array}$ & $\begin{array}{c}\text { Staphylococcus } \\
\left.\text { (UFC.g }^{-1}\right)\end{array}$ & $\begin{array}{c}\text { Salmonella } \\
\text { sp. }\end{array}$ \\
\hline SI1 & $3,36^{c} \pm 0,03$ & $3,28^{d} \pm 0,04$ & $>11.000$ & 150 & $<1,0 \times 10^{1}$ & ausência \\
\hline $\mathrm{SI} 2$ & $3,04^{d} \pm 0,04$ & $3,16^{\mathrm{e}} \pm 0,07$ & $>11.000$ & 1200 & $<1,0 \times 10^{1}$ & ausência \\
\hline IM1 & $3,34^{\mathrm{c}} \pm 0,03$ & $5,88^{b} \pm 0,01$ & $>11.000$ & $>11.000$ & $<1,0 \times 10^{1}$ & ausência \\
\hline IM2 & $3,19^{c d} \pm 0,11$ & $5,96^{\mathrm{b}} \pm 0,01$ & $>11.000$ & $>11.000$ & $<1,0 \times 10^{1}$ & ausência \\
\hline IE1 & $5,18^{\mathrm{b}} \pm 0,03$ & $5,63^{c} \pm 0,03$ & $<3$ & $<3$ & $<1,0 \times 10^{1}$ & ausência \\
\hline IE2 & $5,17^{b} \pm 0,06$ & $2,40^{f} \pm 0,00$ & $<3$ & $<3$ & $<1,0 \times 10^{1}$ & ausência \\
\hline IF1 & $7,17^{a} \pm 0,08$ & $1,30^{g} \pm 0,06$ & 9,2 & 9,2 & $<1,0 \times 10^{1}$ & ausência \\
\hline IF2 & $7,04^{a} \pm 0,13$ & $6,38^{\mathrm{a}} \pm 0,04$ & 16 & 15 & $<1,0 \times 10^{1}$ & ausência \\
\hline
\end{tabular}

SI - sem inspeção; IM - inspeção municipal; IE - inspeção estadual; IF - inspeção federal. UFC - Unidade Formadora de Colônia. NMP - Número Mais Provável.

*Resultados expressos como média \pm desvio padrão $(n=3)$. Letras diferentes na mesma coluna indicam diferença significativa entre as médias pelo teste de Tukey $(p<0,05)$.

Segundo Feitosa et al. (2003), esse tipo de contaminação compromete a qualidade e a vida de prateleira do produto, uma vez que bolores e leveduras são potenciais deterioradores de produtos lácteos. De acordo com Zacarchenco et al. (2011), para controle de bolores e leveduras é necessária excelente higiene da planta de processamento, pois estes deteriorantes são contaminantes amplamente distribuídos no ambiente.

De acordo com a legislação, o limite máximo de coliformes a $30^{\circ} \mathrm{C}$ (totais) para queijos com média umidade é $5.000 \mathrm{NMP} / \mathrm{g}$, enquanto que para queijos com alta umidade o máximo é $10.000 \mathrm{NMP} / \mathrm{g}$ (BRASIL, 1996). Dentre as amostras analisadas, 4 estavam acima dos padrões estabelecidos pela legislação para coliformes totais, sendo 2 amostras de inspeção municipal e 2 amostras sem inspeção. Com relação aos coliformes termotolerantes, a legislação estabelece o máximo de $500 \mathrm{NMP} / \mathrm{g}$ para queijos com média umidade e $5.000 \mathrm{NMP} / \mathrm{g}$ para queijos com alta umidade (BRASIL, 1996). A partir dos resultados, observou-se que 2 amostras estavam em desacordo com os padrões da legislação, sendo ambas de inspeção municipal. As amostras sem inspeção, apesar de terem apresentado elevados valores para coliformes totais não apresentaram contagens acima do estabelecido pela legislação para coliformes termotolerantes. Os queijos com inspeção estadual e federal tiveram contagens baixas tanto de coliformes totais quanto de termotolerantes.

Desta forma, $50 \%$ das amostras analisadas foram caracterizadas como impróprias para 
o consumo, devido à elevada contaminação por coliformes. O mesmo resultado foi observado em estudos realizados por Dias (2010), Oliveira (2011) e Oliveira, Bravo e Tonial (2012). Essa contaminação indica condições higiênico-sanitárias insatisfatórias no processo, bem como uma possível contaminação pós-fabricação. Além disso, apesar do fato de que o queijo deve ser feito com leite pasteurizado, nos laticínios com inspeção municipal é utilizada a pasteurização lenta e muitas vezes a eficiência dos equipamentos disponíveis não é adequada. Já em relação aos queijos sem inspeção a grande contaminação pode ser devido à utilização de leite cru, o qual já pode estar contaminado. Freitas Eduardo (2008) afirma que a falta de conhecimento de boas práticas de fabricação por parte dos produtores, que fazem o queijo artesanalmente, sem controle do processo de fabricação também pode contribuir para a contaminação.

Segundo a legislação, os queijos com alta e média umidade devem possuir contagens de Staphylococcus inferiores a 1.000 UFC/g (BRASIL, 1996). As médias encontradas foram $<1,0$ $\times 10^{1} \mathrm{UFC} . \mathrm{g}^{-1}$ para todas as amostras analisadas, abaixo do máximo estabelecido pela legislação, desta forma aptas para o consumo. Resultados similares foram observados no estudo de Oliveira (2011), onde todas as amostras estavam em concordância com a legislação. Em contrapartida, em pesquisas realizadas por Antonello, Kupkovski e Bravo (2012) e Oliveira, Bravo e Tonial (2012), $82,14 \%$ e $100 \%$ das amostras, respectivamente, apresentaram contagens acima dos valores máximos estabelecidos, o que oferece perigo à saúde dos consumidores. Segundo Franco (2008), - Staphylococcus coagulase positiva é um indicador de falha de manipulação e microrganismo patógeno causador de intoxicação alimentar.

A inocuidade do queijo colonial em relação à presença de Staphylococcus coagulase positiva é necessária e imprescindível a este produto, na garantia da qualidade e, principalmente na segurança alimentar do queijo, que é oferecido ao consumidor do sudoeste do Paraná, se fazendo necessário o uso de boas práticas na fabricação e constante treinamento dos colaboradores.

Segundo a legislação, os queijos não devem possuir contaminação por Salmonella sp. em $25 \mathrm{~g}$ de amostra (BRASIL, 1996), uma vez que é um patógeno potencial causador de infecção alimentar (FRANCO, 2008). Dentre as amostras analisadas nenhuma apresentou contaminação pelo microrganismo, em conformidade com os padrões da legislação vigente. Os mesmos resultados foram encontrados por Oliveira (2011), com estudos na região. Por outro lado, Dias (2010), Antonello, Kupkovski e Bravo (2012) e Oliveira, Bravo e Tonial (2012) observaram 10\%, 17,85\% e 12,5\% das amostras com resultados positivos para Salmonella, respectivamente. Assim pode-se destacar a importância de boas práticas de fabricação e controle na produção de queijos coloniais, uma vez que estudos realizados na região indicaram a presença do patógeno, o qual deve estar isento no produto.

\section{CONCLUSÃO}

A partir dos resultados obtidos, observou-se que existe uma heterogeneidade entre os queijos de diferentes níveis de inspeção avaliados. Os queijos com inspeções federal e estadual apresentam melhor padronização em seu processo e produto, qualidade e segurança alimentar. No entanto, todas as amostras de queijos com inspeção municipal e sem inspeção apresentaram contaminação por coliformes.

A elevada contaminação das amostras pode indicar procedimentos higiênicos insatisfatórios durante a fabricação, transporte e comercialização dos queijos, manutenção em temperatura inadequada e ao uso de matéria-prima de baixa qualidade higiênica, como leite não pasteurizado, o que causa preocupação por ser um risco à saúde do consumidor.

Dessa forma, faz-se necessária a elaboração de um regulamento técnico de identidade e qualidade do queijo colonial, a fim de padronizar seu processo de fabricação, com consequente padronização do produto, uma vez que houve variação entre a maioria dos aspectos físico-químicos avaliados, o que interfere diretamente na composição, sabor, aroma e textura final deste tipo de 
queijo. Além disso, devem ser realizados treinamentos e implantação de boas práticas de fabricação para produtores com inspeção municipal e sem inspeção, o que contribuiria para a melhor qualidade do queijo colonial oferecido aos consumidores.

\section{ABSTRACT \\ MICROBIOLOGICAL AND PHYSICO-CHEMICAL QUALITY OF COLONIAL CHEESES WITH AND WITHOUT INSPECTION, MARKETED IN SOUTHWESTERN PARANÁ}

The colonial cheese is an artisanal cheese produced on farms, usually made with raw milk and often without good manufacturing practices. It does not have technical regulation of identity and quality and in many cases has no inspection. The objective of this study was to evaluate the physico-chemical characteristics and microbiological quality of samples of colonial cheeses without inspection, with federal, state and municipal inspection marketed in southwestern Paraná. Eight samples of colonial cheese, two of each inspection service and two without inspection were collected. Physico-chemical analysis $(\mathrm{pH}$, acidity, moisture, protein, lipid, fat in dry matter, solids non fat, ash and total carbohydrates) and microbiological (mesophilic aerobic, yeasts and molds, total and fecal coliforms, Staphylococcus coagulase positive and Salmonella sp.) were carried out. The results of these analyzes showed that $50 \%$ of the samples were with counts of total and fecal coliforms above those permitted by legislation (two samples without inspection and two samples with municipal inspection). By means of physico-chemical analysis, it was possible to observe the lack of standardization of colonial cheeses, which is undesirable both for producers and for consumers. Thus, it is necessary a higher quality control of the process and the final product as well as the preparation of a technical regulation of identity and quality of colonial cheese.

KEY-WORDS: RAW MILK; COLONIAL CHEESE; DAIRY; CONTAMINATION; INSPECTION.

\section{REFERÊNCIAS}

$1 \quad A B I Q$ - Associação Brasileira das Indústrias de Queijo. Benefícios nutricionais dos queijos. Disponível em: http://www.abiq.com.br/nutricao_7.asp. Acesso em: 12 mai 2014.

2 ANDRADE, A.A. de. Estudo do perfil sensorial, físico-químico e aceitação de queijo de coalho produzido no estado do Ceará. 104p. 2006. Dissertação (Mestrado em Tecnologia de Alimentos) Universidade Federal do Ceará, Fortaleza, 2006.

3 ANTONELLO, L; KUPKOVSKI, A.; BRAVO, C.C. Qualidade microbiológica de queijos coloniais comercializados em Francisco Beltrão, Paraná. Revista Thema, v.9, p.1-6, 2012.

4 AOAC INTERNATIONAL. Official methods of analysis. $18^{a}$ ed., $3^{a}$ rev. Arlington, VA, EUA: AOAC International, 2005.

5 BRASIL. Ministério da Agricultura, Pecuária e Abastecimento - MAPA. Instrução Normativa $n^{\circ} 62$, de 26 de agosto de 2003. Oficializar os Métodos Analíticos Oficiais para Análises Microbiológicas para Controle de Produtos de Origem Animal e Água. Diário Oficial da União, Brasília, DF,18 setembro 2003, sec.1, p.14.

6 BRASIL. Ministério da Agricultura, Pecuária e Abastecimento - MAPA. Portaria n¹46, de 07 de março de 1996. Aprova os Regulamentos Técnicos de Identidade e Qualidade dos Produtos Lácteos. Diário Oficial da União, Brasília, DF, 11 março 1996, sec.1, p.3977.

7 BITTENCOURT, R.H.F.P.M. Requeijão Marajoara e queijo Minas Frescal produzidos com leite de búfalas (Bubalus Bubalis, Lin.) no estado do Pará. 2011. 106p. Tese (Doutorado em Medicina Veterinária) - Universidade Federal Fluminense, Niterói, 2011.

$8 \mathrm{CECCHI}, \mathrm{H}$. M. Fundamentos teóricos e práticos em análise de alimentos. $2^{\circ}$ Ed. Campinas, SP: Editora da Unicamp, 2003. 
9 COSTA, F. M. A; D'ALESSANDRO W.T.; CARVALHO, A.L.; ROCHA J.M.; TANEZINI, C.A.; PONTES, I.S.; FERREIRA M.L.; SOTÉRIO, N.M.F. Variação do teor de gordura no leite bovino cru. Pesquisa Agropecuária Brasileira, v. 27, p. 763-769, 1992.

10 DIAS, V.A. Qualidade microbiológica do queijo colonial produzido e comercializado na região Sudoeste do Paraná. 2010. Trabalho de Conclusão de Curso (Graduação em Economia Doméstica) Universidade Estadual do Oeste do Paraná (UNIOESTE), Francisco Beltrão, 2010.

11 FEITOSA, T.; BORGES, M.F.; NASSU, R.T; AZEVEDO, E.H.F; MUNIZ, C.F. Pesquisa de Salmonella sp., Listeria sp. e microrganismos indicadores higiênico-sanitários em queijos produzidos no Estado do Rio Grande do Norte. Ciência e Tecnologia de Alimentos, v.23, p.162-165, 2003.

12 FRANCO, B. D. G. M.. Microbiologia de alimentos. São Paulo: Atheneu, 2008.

13 FREITAS EDUARDO, M. A dinâmica territorial das agroindústrias artesanais de Francisco Beltrão/ PR. 2008. 166p. Dissertação (Mestrado em Geografia) - Universidade Estadual Paulista, Presidente Prudente, 2008.

14 INSTITUTO ADOLFO LUTZ. Normas Analíticas do Instituto Adolfo Lutz. Métodos químicos e físicos para análise de alimentos, 4. ed. São Paulo: IMESP, 2008.

15 JÚNIOR, J.F.S; OLIVEIRA, D.F.; BRAGHINI, F.; LOSS, E.M.S.; BRAVO, C.E.C.; TONIAL, I.B. Caracterização físico-química de queijos coloniais produzidos em diferentes épocas do ano. Revista Instituto de Laticínios “Cândido Tostes", v. 67, p. 67-80, 2012.

16 JUNIOR, S. L. G., PENTEADO, S. T. da S., FARIÑA, L.de O. Avaliação da qualidade do queijo produzido pela agricultura familiar no Oeste e Sudoeste do Paraná. In: XIX Encontro Anual de Iniciação Científica, Universidade Estadual do Oeste do Paraná, Cascavel - PR, 2010. Anais... Cascavel: UNIOESTE, 2010.

17 LEITE JÚNIOR, A.F.S; FLORENTINO E.R.; OLIVEIRA, N.E.B; AS, S.N.E.; TORRANO, A.D.M. Qualidade microbiológica do queijo de coalho comercializado à temperatura ambiente ou sob refrigeração, em Campina Grande - PB. Revista Higiene Alimentar, v. 14, p. 53-59, 2000.

18 LUCAS, S. D.M.; SCALCO, A.; FELDHAUS, S.; DRUNKLER, D.A.; COLLA, E. Padrão de identidade e qualidade de queijos Colonial e Prato, comercializados na cidade de Medianeira - PR. Revista Instituto de Laticínios "Cândido Tostes”, v. 67, p. 38-44, 2012.

19 MAGALHÃES, F. A. R. Evolução de características físico-químicas e sensoriais durante a maturação do queijo tipo gorgonzola. 2002. 85 f. Tese (Doutorado em Ciência dos Alimentos) - Universidade Federal de Lavras, Lavras, Minas Gerais. 2002.

20 NORONHA, J. F. de. Segurança alimentar dos queijos tradicionais. Disponível em: <http://www.esac. pt/noronha/manuais/seguranca_alimentar_queijos.pdf>. Acesso em: 10 fev. 2014.

21 OLIVEIRA, D. F.de. Estudo da interferência da sazonalidade na composição centesimal e qualidade microbiológica de queijos coloniais. 2011. 40p. Trabalho de conclusão de curso (Graduação em Tecnologia em Alimentos) - Universidade Tecnológica Federal do Paraná, Francisco Beltrão, 2011.

22 OLIVEIRA, D.F.; BRAVO, C.E.C.; TONIAL, I. B. Sazonalidade como fator interferente na composição físicoquímica e avaliação microbiológica de queijos coloniais. Arquivo Brasileiro de Medicina Veterinária e Zootecnia, v.64, p.521-523, 2012.

23 PERRY, K. S. P. Queijos: aspectos químicos, bioquímicos e microbiológicos. Química Nova, v.27, p. 293300, 2004.

24 PEREIRA, D. B. C.; SILVA, P. H. F.; OLIVEIRA, L. L.; COSTA JÚNIOR, L. C. G. C. Físico-química do leite e derivados - Métodos analíticos. 1.ed. Juiz de Fora-MG: Oficina de Impressão Gráfica e Editora Ltda, 2001. $190 \mathrm{p}$.

25 ROOS, T.B; SCHEID, F.V.B; TIMM, C.D.; OLIVEIRA, D.S. Avaliação microbiológica de queijos coloniais produzidos na cidade de Três Passos, RS. Higiene Alimentar, v.19, p. 94-96, 2005.

26 SEBRAE. Serviço Brasileiro de Apoio às Micro e Pequenas Empresas. Queijos Nacionais. Estudo de mercado SEBRÁE/ESPM. Relatório completo, 2008.

27 SCOTT, R.; ROBINSON, R. K; WILBEY, R. A. Fabricación de queso. 2. ed. Zaragoza: Acribia, 2002. 488 p.

28 SPREER, E. Lactologia industrial. 2.ed. Zaragoza: Acribia, 1991. 617 p.

29 STATSOFT INC. Statistical data analysis system version 7.0. Tulsa: Statsoft Inc., 2004.

30 TEDESCO, J. M.; GIANELLO, C.; BISSANI, A. C.; BOHNEN, H. E; VOLKWEISS, S. J. Análise de solo, plantas e outros materiais. Boletim Técnico 5. Porto Alegre, RS, 1995. 
31 VERZA, M. Caracterização do sistema de produção de leite do munícipio de Jupiá - SC. 2012. 110p. Dissertação (Mestrado em Agroecossistemas) - Universidade Federal de Santa Catarina, Florianópolis, 2012.

32 ZACARCHENCO, P. B.; TRENTO, F.K.H.S.; SPADOTI, L.; GALLINA, D. A.; SILVA, A.T. Bolores e leveduras em queijos. Revista Leite \& Derivados, ano XX, n 129, p.92-99, 2011. 